\title{
Patterns of Stationary Activities in the Elevated Pedestrian Networks of High- Density Asian Cities: The case of Mong Kok, Hong Kong
}

\author{
Caterina Villani, Gianni Talamini \\ Department of Architecture and Civil Engineering, \\ City University of Hong Kong, Tat Chee Avenue, Kowloon, Hong Kong SAR, China \\ cvillani2-c@my.cityu.edu.hk, gianntal@cityu.edu.hk \\ Tel: +85262244234
}

\begin{abstract}
Urban areas are increasingly failing to provide citizens with adequate and quality public open spaces. In this regard, Hong Kong characterises an extreme condition with $2.7-2.8 \mathrm{~m}^{2}$ of open space per capita. The burden of this scarcity falls most heavily on economically disadvantaged social groups, such as migrant domestic workers. In this context, grade separation pedestrian systems that were originally designed for mobility purposes, can provide space for sociability-oriented stationary uses. This study finds that the density of stationary activities in a typical elevated pedestrian network is as high as 1.2 person $/ \mathrm{m}^{2}$.
\end{abstract}

Keywords: Skywalk; Behavioural mapping; Stationary uses; Hong Kong

eISSN: 2398-4287 @ 2019. The Authors. Published for AMER ABRA cE-Bs by e-International Publishing House, Ltd., UK. This is an open access article under the CC BYNC-ND license (http://creativecommons.org/licenses/by-nc-nd/4.0). Peer-review under responsibility of AMER (Association of Malaysian Environment-Behaviour Researchers), ABRA (Association of Behavioural Researchers on Asians) and cE-Bs (Centre for Environment-Behaviour Studies), Faculty of Architecture, Planning \& Surveying, Universiti Teknologi MARA, Malaysia.

DOI: https://doi.org/10.21834/e-bpj.v4i12.1905

\subsection{Introduction}

Current academic research, international organisations and planning practice increasingly recognise that urban spaces will need to cater to mobility functions - mobile uses - as well as public space functions - stationary activities - in cities worldwide (Agyeman \& Zavestoski, 2015; UN-Habitat, 2013). Specifically, mobility transition studies (Nikolaeva et al., 2019) recommend reconceptualising urban spaces, so as to balance movement by different modes of transport (pedestrians, bicycles and motorised vehicles) as well as lingering and other stationary uses (social interactions and cultural expressions) in the planning of urban streets (Von Schönfeld \& Bertolini, 2017), transport stations and pedestrian networks.

Grade separation pedestrian systems (GSPS) include underground pedestrian systems and elevated pedestrian networks (EPNs) (often referred to as skywalks or elevated walkways) and well characterised spaces planned to accommodate pedestrian mobility (Robertson, 1993; Tan \& Xue, 2014). These networks commonly interconnect high-rise commercial or office buildings with activity hubs, such as transport stations, in the dense urban core of numerous cities worldwide. GSPS are proposed both as solutions to congested traffic street networks and as a means to enhance pedestrian access to shopping precincts (Cui, Allan, \& Lin, 2013; Robertson, 1993). Although it was initially implemented in North American cities, EPNs of high-density Asian cities such as Hong Kong, Shanghai, Mumbai, Singapore, Kuala Lumpur and Bangkok have experienced increased development over the past 40 years. Relevant studies demonstrated that EPNs significantly improve mobility and the economic activity of the surrounding urban areas (Corbett, Xie, \& Levinson, 2009; Wan, 2010). Despite this, limited research on the impact of EPNs on public space provision (specifically for vulnerable social groups) and stationary activity opportunities has produced mixed results (Maitland, 1992; Robertson, 1993). Besides, evidencebased analysis of stationary activity patterns of EPNs remains mostly unexplored.

eISSN: 2398-4287 @ 2019. The Authors. Published for AMER ABRA cE-Bs by e-International Publishing House, Ltd., UK. This is an open access article under the CC BYNC-ND license (http://creativecommons.org/licenses/by-nc-nd/4.0). Peer-review under responsibility of AMER (Association of Malaysian Environment-Behaviour Researchers), ABRA (Association of Behavioural Researchers on Asians) and cE-Bs (Centre for Environment-Behaviour Studies), Faculty of Architecture, Planning \& Surveying, Universiti Teknologi MARA, Malaysia. DOI: https://doi.org/10.21834/e-bpj.v4i12.1905 
This study investigates the EPNs of Hong Kong, well-known internationally for its comprehensive EPN system, by focussing on the case of the EPN in Mong Kok (MK). The district is one of the city's densest, most commercially active, and with below standard public space provision (Xue, Manuel, \& Chung, 2001). The MK EPN emerged as a particularly representative case for the substantial level of stationary use by migrant domestic workers (MDWs) observed during preliminary site visits. Firstly, this study illustrates the network development rationale and the accessibility to services provided by it. Secondly, as a novel setting for environment-behaviour research, it analyses stationary activities during the peak hours of the day during weekends when MDWs assemble in this space.

Specifically, in this paper, our research questions are as follows:

1) How many stationary activities can the EPN cater to? How do stationary uses vary with weather conditions?

2) Which types of stationary activities are observable in the EPN?

3) To what extent does the EPN environment support these recurring patterns of behaviour?

This study attempts to contribute to the limited literature on the impact of GSPS on public space provision in the Asian context. Additionally, it provides useful insights for a future-inclusive approach to the design of EPNs, which take into account stationary activities.

\subsection{Literature Review}

Over the last decade, relevant research has been focussing on the impact of GSPS on public space provision, especially in North American cities (Cui, Allan, \& Lin, 2013). Notable studies assessed these through the contribution of GSPS strategies to:

1) The design for the provision of open public spaces,

2) The availability of public services and amenities, and

3) Access to these pedestrian environments by marginalised social groups

The GSPS are studied as environments primarily designed to accommodate pedestrian flow, without sitting and resting opportunities (Robertson, 1993). In addition, GSPS are mainly developed in privately-owned and managed environments (e.g., commercial centres), and this poses some challenges to the wide public access after the buildings' opening hours (Robertson, 1993). Although the indoor environments there might be publicly accessible services, the use by social groups with a low buying power, made the management limit access to these amenities, as in Montreal (Maitland, 1992). Research suggests that through GSPS, the physical separation with street-level public space and exclusive connection with office or high-end commercial buildings might result in social separation, as observed in several US cities (Terranova, 2009). Limited research is being undertaken with respect to the impact of GSPS on public space provision in high-density Asian cities (Cui, Allan, \& Lin, 2013), where the development of GSPS is booming. In Tokyo, Osaka, Hong Kong, Shanghai, and Mumbai, the GSPS was introduced as a pedestrian and vehicular traffic separation measure. The GSPS soon became a space for the local elite in Mumbai (Harris, 2018). In Shanghai and Hong Kong, GSPS eventually turned into a means to establish a landscape of consumption between shopping centres (Tan \& Xue, 2014; Villani, 2018; Zacharias \& He, 2018). This is also evident in the underground system design of Shanghai, presenting inadequate availability of public facilities and access points (Cui, Allan, Taylor, \& Lin, 2013).

From limited studies of GSPS in Asian cities, it also emerged that outside office hours, when the pedestrian flow reduces, these mobility spaces might be used for a variety of stationary uses by different social groups in need of space (Harris, 2018). In Shanghai, homeless people use some underground systems as a sheltered sleeping place during the night (Cui, Allan, Taylor, et al., 2013). Similarly, in Mumbai, 'slum' residents use the skywalk above their neighbourhood to sit and relax after office hours (Harris, 2018). In Hong Kong, the setting of this study, similar phenomena are more visible and involve several urban districts that every Sunday become places of MDWs' social and cultural gathering (Law, 2001; Villani, Zordan, Talamini, \& Cheng, 2019; Wang, Siu, \& Wong, 2016).

\subsection{Research Approach and Methodology}

This paper adopts a case study approach. This is suitable when the knowledge obtainable from the case study can potentially advance the understanding of a specific topic (Yin, 1984). Since the literature reveals that in the Asian context, research on the impact of GSPS' development is limited, and the research on stationary uses of EPN is unexplored, a case study is considered appropriate. Specifically, Cui et al. (2013) support the case study research on EPN, suggesting to consider "special and unique social situations of each city [...] because the effects of GSPS were highly dependent on the individual milieu” (p.159). This study was set in Hong Kong, internationally recognised as one of the highest-density cities in the world. Hong Kong is characterised by a vertical and compact urban form, which triggered the development of multilevel pedestrian networks interconnecting commercial or office buildings and activity or transportation hubs since the 1960s (Tan \& Xue, 2014). In total, there are around 700 elevated pedestrian bridges in Hong Kong (Wang et al., 2016). At the same time, it is recognised that an open public space is a quantitatively and qualitatively limited resource in the city (Rossini, 2019; Tang, 2017). This is observed to be a well-established setting for large gatherings of MDW groups - mainly young women from Southeast Asia - every Sunday, which is their stipulated day off (Law, 2001).

\subsection{Case Study}

The EPN in MK, Kowloon peninsula, was selected as a "revelatory case" (Yin, 1984) of the EPNs in Hong Kong. MK is an old urban neighbourhood with mixed-land use in the district of Yau Tsim Mong (Fig.1a). It is characterised by a combination of tall commercial and residential buildings and is a highly popular commercial destination for locals and tourists. MK is a major transport interchange for public transportation, with two railway stations: MK station and MK East station. With a high population density of $82,151 / \mathrm{km}^{2}$ (HKSAR Census 
and Statistics Department, 2016) and a far-below-standards open public space provision of 8.1 hectares (Xue et al., 2001), MK exemplifies an extreme urban condition.

The MK EPN construction was funded by a private developer, the Sun Hung Kei Properties Charitable Fund Limited, and it was completed in 2003 (Lam \& Kung, 2004). The purpose of the network was to provide higher pedestrian accessibility between the two railway stations and the commercial property connected, MOKO mall, owned by the developer. The EPN (Fig.1b) spans about $400 \mathrm{~m}$ along two traffic arteries, MK Road and Sai Yee Street. The widths of the walkway are 8.5m along MK Road and 5.5m along Sai Yee Street. The EPN can be accessed through escalators or staircases situated in six locations along MK Road, and lifts were installed in four locations. The first part, across MK Road, is linked to the B3 exit of MK station, while the second part across Sai Yee Street is linked to the MOKO shopping mall and MK East station. Although the construction of MK EPN was supported by a private developer to attract and channel pedestrian flow between transport stations and commercial complexes, the EPN is categorised as a public space, managed and maintained by the HK Government. This makes the place an accessible destination for MDWs' leisure activities; it also caters to the MDWs commercial demand (Fig.1).

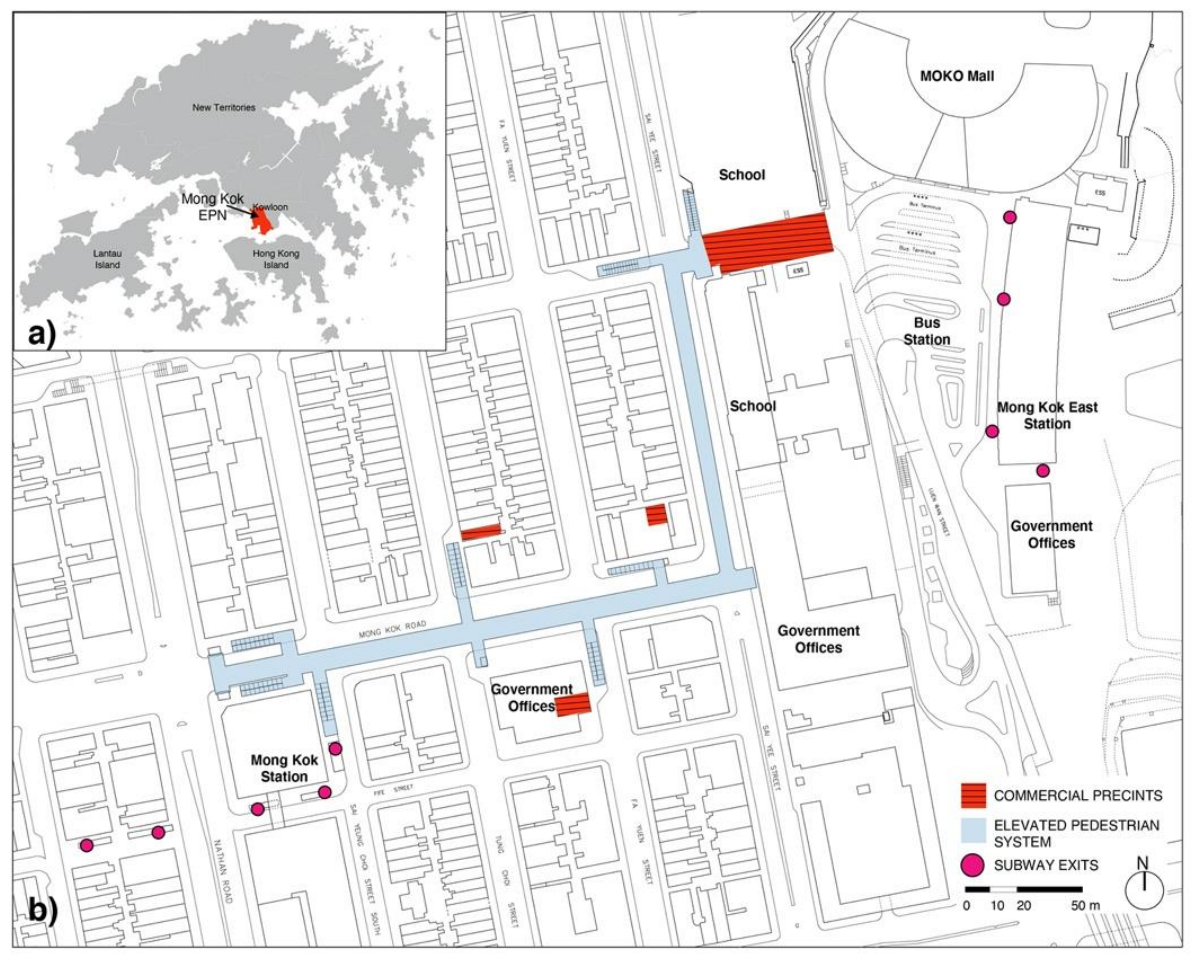

Fig. 1: a) Location of MK EPN in Yau Tsim Mong District. B) Map of MK EPN (Source: Caterina Villani based on Hong Kong OZP)

\subsection{Videography and Behavioural Mapping}

This study applied two tools of environment-behaviour research: videography (and snapshot observations), and behavioural mapping. These tools are adopted in order to analyse the patterns of stationary uses in the MK EPN. These tools are unobtrusive observational methods that allow associating the design characteristics of the environment with behaviour information of the occupants while recording location and time (Bechtel \& Zeisel, 1987; Goličnik Marušic, 2016; Hanan, 2017; Whyte, 1980). Videography was complementary to behavioural mapping and a standalone method to record behaviours in crowded environments as previously adopted (Wang et al., 2016). The initial phase of behavioural mapping involves the extensive observation of the designed setting, the development of a base map, and the classification of the types of activities to be observed (Goličnik Marušic, 2016; Rasidi, Jamirsah, \& Said, 2012). The observed activities are then recorded on a GIS platform (Tammikakul \& Raksawin, 2019) and rendered through different types of maps and tables. This study applies the Dot Distribution Map to visualise the occurrence and patterns of stationary activities. The choice of these methods was influenced by the seminal work of William H. Whyte and Jan Gehl (Gehl, 1987; Whyte, 1980). More recent studies apply behavioural mapping by focussing on parks (Ghavampour, Del Aguila, \& Vale, 2017), urban streets (Elsheshtawy, 2013; Mehta, 2009), informal street markets (Sun, Bell, Scott, \& Qian, 2019) or public squares (Cheshmehzangi \& Heath, 2017) as behavioural settings.

\subsection{Data Collection}

Data collection was organised into two phases. The first one consisted in the development of the MK EPN area base map. Data were collected from the Outline Zoning Plan (OZP) of Hong Kong (Chapter 131, Laws of Hong Kong), recorded on the GIS data set, and integrated with primary spatial data of EPN design collected on site. The second phase comprised stationary uses data collection, which involved recording locational and categorical information on stationary activities (such as sitting and standing) of occupants. The on-site 
observations were recorded during ten site visits from October to December 2018, as mild-climate months. The extensive on-site visits were set in order to cover different weather conditions. Sunday was selected as the observation day, primarily because it was MDWs weekly day off and governmental offices remained closed. The observations were made from 3 p.m. to 4 p.m. as a recognised peak time for MDWs' social activities in Hong Kong (Law, 2001). The data collection protocol followed the walk-through method (Elsheshtawy, 2013), consisting of a pre-defined walking itinerary that covered the entire EPN. Data consistency and trustworthiness were achieved using videography for observation recording. Stationary activities were coded as data points on the EPN base map on GIS. The stationary activities were distinguished as individual (e.g., standing or sleeping), social activities (Gehl, 1987), or production-oriented activities (e.g., preparing food). The categorisation of stationary activities types was informed by relevant literature of MDWs' leisure activities (Law, 2001; Tillu, 2011). The total recorded behavioural observations are 14,765.

\subsection{Limitations of Methodology}

The following are the limitations associated with the methodology: First, the case study focussed on the EPN in MK; other forms of public spaces, which may show similar phenomena were not selected. Second, walking activities were not considered for the data collection. Third, due to the changing nature and overcrowded conditions, the stationary activities' category is unlikely to fully represent the actions that the MDWs perform. The investigation on the location choice for these stationary activities is outside the scope of this study.

\subsection{Findings}

The 14,765 recorded stationary activities were reported through the Dot Distribution Map (Fig. 2) to visualise the activity density across the MK EPN for ten site visits. The overall activities' data comprise the population number and density (Table 1). The average number of observed stationary activities is 1476.5 , the highest population is observed during rainy conditions (1642 observations), when it recorded about $10 \%$ of population increase from the average population. The average occupancy follows a similar trend; the whole EPN registers 0.4 person $/ \mathrm{m}^{2}$. Although this remains constant throughout the observation period, during rainy weather, it reaches 0.5 person $/ \mathrm{m}^{2}$, which is equal to $2 \mathrm{~m}^{2} /$ person.

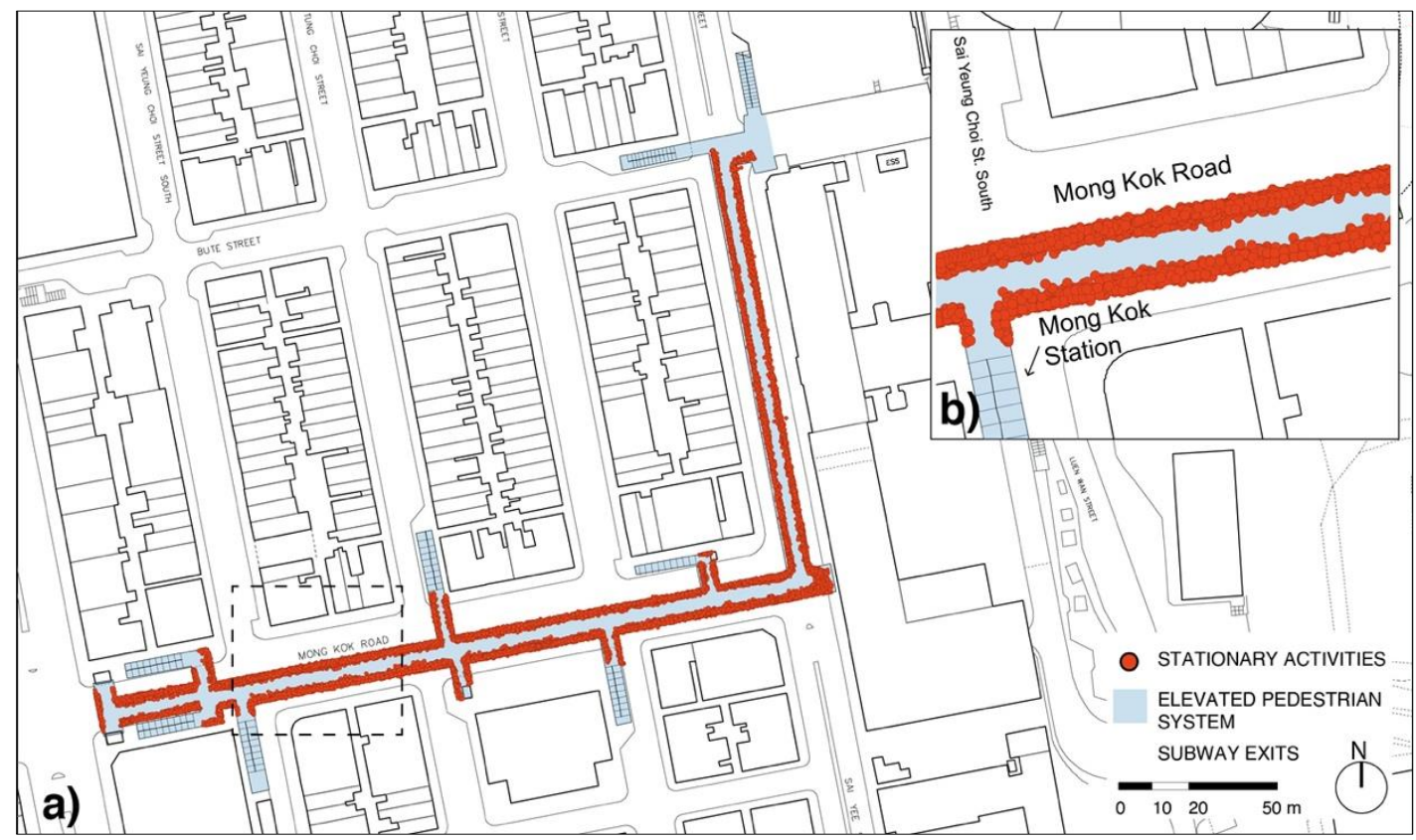

Fig. 2: Dot Distribution Map of Stationary activities in the EPN (Source: Caterina Villani and Cheng Yuk Ming)

Table 1. Activities and density per observation period

\begin{tabular}{|c|c|c|c|}
\hline Period & Weather Condition & Observations & Density [person $/ \mathrm{m}^{2}$ ] \\
\hline Day 1 & $28^{\circ} \mathrm{C}$, Sunny day & 1470 & 0.4 \\
\hline Day 2 & $25^{\circ} \mathrm{C}$, Cloudy day & 1459 & 0.4 \\
\hline Day 3 & $25^{\circ} \mathrm{C}$, Cloudy day & 1512 & 0.4 \\
\hline Day 4 & $24^{\circ} \mathrm{C}$, Sunny day & 1460 & 0.4 \\
\hline Day 5 & $24^{\circ} \mathrm{C}$, Cloudy day & 1493 & 0.4 \\
\hline Day 6 & $24^{\circ} \mathrm{C}$, Cloudy day & 1405 & 0.4 \\
\hline Day 7 & $24^{\circ} \mathrm{C}$, Cloudy day & 1560 & 0.4 \\
\hline Day 8 & $19^{\circ} \mathrm{C}$, Rainy day & 1642 & 0.5 \\
\hline Day 9 & $19^{\circ} \mathrm{C}$, Cloudy day & 1441 & 0.4 \\
\hline \multirow[t]{2}{*}{ Day 10} & $15^{\circ} \mathrm{C}$, Cloudy day & 1323 & 0.4 \\
\hline & Average & 1476.5 & 0.4 \\
\hline
\end{tabular}


The stationary activities were further analysed through the categorisation of activities type. This was done through snapshot observations (Fig. 3, Table 2). In the EPN, the preferred activities were social (90\%), followed by individual ( $8 \%$ ) and production-oriented $(2 \%)$ actions. Among these macro-categories, MDWs prefer to chat $(87 \%)$ and stand $(5 \%)$ as social and individual activities, respectively.

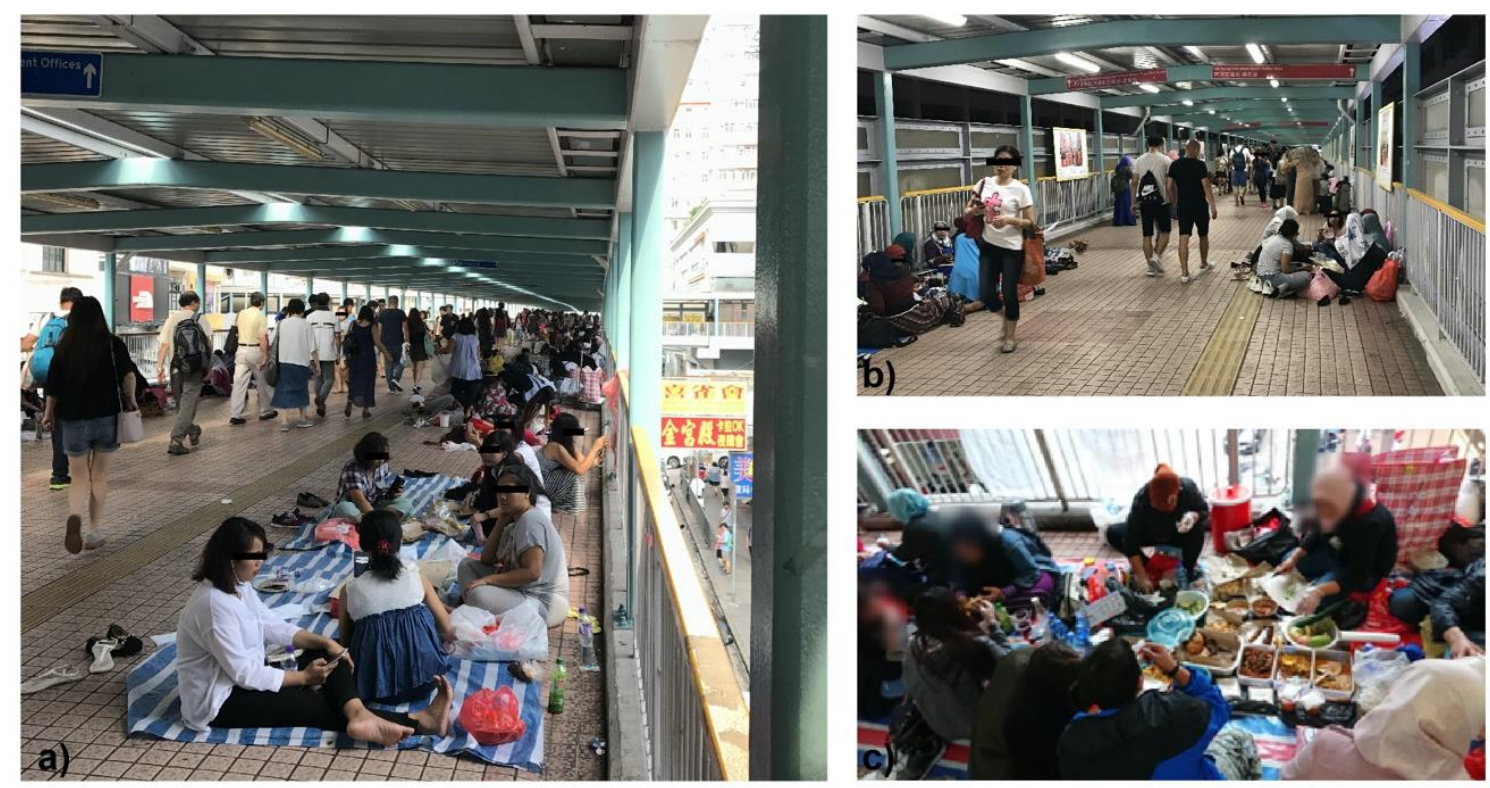

Fig. 3: a) Snapshot of stationary activities in the EPN Part 1. b) Snapshot of stationary activities in Part 2. c) Snapshot of MDWs preparing food (Source: Caterina Villani and Cheng Yuk Ming)

Table 2. Types of activities per observation period

\begin{tabular}{|c|c|c|c|c|c|c|c|}
\hline \multirow[t]{2}{*}{ Period } & \multicolumn{2}{|c|}{ Individual } & \multicolumn{4}{|c|}{ Social } & \multirow{2}{*}{$\begin{array}{l}\text { Production-oriented } \\
\text { Preparing food }\end{array}$} \\
\hline & $\begin{array}{l}\text { Laying } \\
\text { down }\end{array}$ & Standing & Chatting & Singing & Taking a selfie & Sharing food & \\
\hline Day 1 & $6 \%$ & $4 \%$ & $82 \%$ & $1 \%$ & $1 \%$ & $2 \%$ & $4 \%$ \\
\hline Day 2 & $2 \%$ & $5 \%$ & $90 \%$ & $0 \%$ & $1 \%$ & $2 \%$ & $1 \%$ \\
\hline Day 3 & $3 \%$ & $4 \%$ & $88 \%$ & $0 \%$ & $1 \%$ & $2 \%$ & $2 \%$ \\
\hline Day 4 & $5 \%$ & $4 \%$ & $85 \%$ & $0 \%$ & $1 \%$ & $2 \%$ & $2 \%$ \\
\hline Day 5 & $4 \%$ & $4 \%$ & $88 \%$ & $0 \%$ & $1 \%$ & $2 \%$ & $2 \%$ \\
\hline Day 6 & $3 \%$ & $3 \%$ & $90 \%$ & $0 \%$ & $0 \%$ & $2 \%$ & $2 \%$ \\
\hline Day 7 & $1 \%$ & $5 \%$ & $90 \%$ & $0 \%$ & $1 \%$ & $2 \%$ & $1 \%$ \\
\hline Day 8 & $1 \%$ & $4 \%$ & $90 \%$ & $0 \%$ & $1 \%$ & $2 \%$ & $2 \%$ \\
\hline Day 9 & $3 \%$ & $5 \%$ & $86 \%$ & $0 \%$ & $1 \%$ & $3 \%$ & $2 \%$ \\
\hline Day 10 & $1 \%$ & $10 \%$ & $85 \%$ & $0 \%$ & $1 \%$ & $2 \%$ & $2 \%$ \\
\hline $\begin{array}{l}\text { Average } \\
\text { Total }\end{array}$ & $3 \%$ & $5 \%$ & $87 \%$ & $0 \%$ & $\begin{array}{l}1 \% \\
90 \%\end{array}$ & $2 \%$ & $\begin{array}{l}2 \% \\
2 \%\end{array}$ \\
\hline
\end{tabular}

(Source: Caterina Villani)
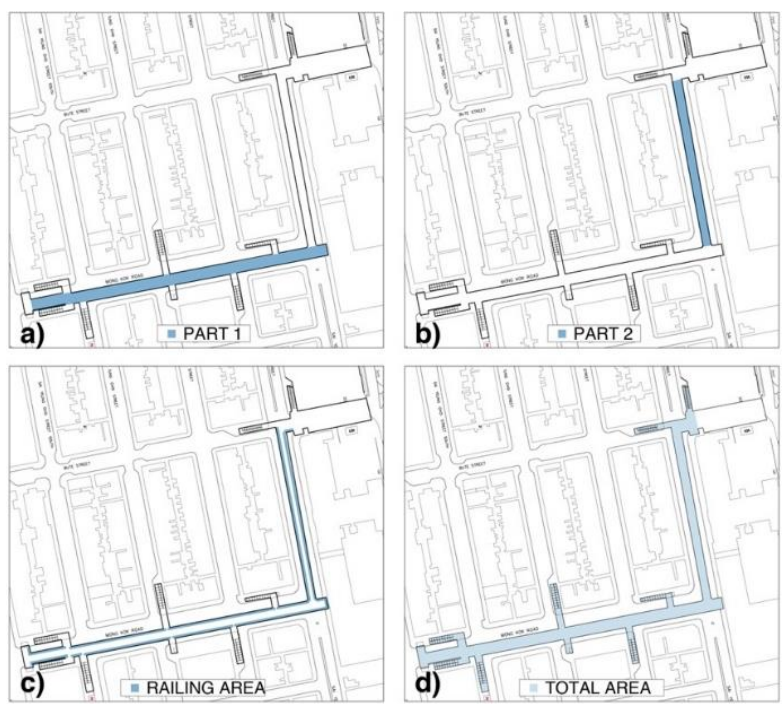

Fig. 4: a) the EPN part 1. b) The EPN part 2. c) The railing space ( $2 \mathrm{~m}$ offset) d) Total EPN area (Source: Caterina Villani) 
As it emerges from the Dot Distribution Map (Fig. 2), and from the snapshot observations (Fig. 3), the occupancy level is higher near specific features of the EPN and close to specific activities. This association was analysed by subdividing the total EPN area into: Part 1 and Part 2 of EPN, and the railing area (Fig 4., Table 3). Besides, the analysis examined for each observation day, the occupancy in the $1 \mathrm{~m}$ buffer from production-oriented activities. Both the EPN Part 1 and Part 2 show an average 0.4 person $/ \mathrm{m}^{2}$ density that is consistent with the total area density (Table 3). During rainy weather, Part 1 shows a slightly higher density $\left(0.5 \mathrm{person} / \mathrm{m}^{2}\right)$ compared to Part 2. One explanation is that Part 1 is wider $(8.5 \mathrm{~m})$ than Part $2(5.5 \mathrm{~m})$, and hence can accommodate a higher population without affecting the pedestrian flow. Although this flow was not counted, snapshot observations recorded activities cluster at both sides of the walkway space, leaving a middle path for pedestrians on the move. The effective space occupied by stationary activities is confined in the $2 \mathrm{~m}$ offset from each side of the railing (Fig. 3 a). This area registers an extremely high occupancy of 1 person $/ \mathrm{m}^{2}$. Finally, stationary behaviours are highly clustering (1.2 person/ $\mathrm{m}^{2}$ ) near MDWs involved in food production activities (Table 3 ).

Table 3. Activities' density per spatial feature

\begin{tabular}{llllll}
\multicolumn{5}{c}{ Table 3. Activities' density per spatial feature } \\
\hline & Part 1 & Part 2 & $\begin{array}{l}\text { Railing } \\
\text { area }\end{array}$ & $\begin{array}{l}\text { Food } \\
\text { preparation } \\
\text { area }\end{array}$ & $\begin{array}{l}\text { Total } \\
\text { Area }\end{array}$ \\
\hline Day 1 & 0.4 & 0.4 & 1.0 & 1.4 & 0.4 \\
Day 2 & 0.4 & 0.3 & 1.0 & 1.2 & 0.4 \\
Day 3 & 0.4 & 0.4 & 1.0 & 1.4 & 0.4 \\
Day 4 & 0.4 & 0.4 & 1.0 & 1.3 & 0.4 \\
Day 5 & 0.4 & 0.4 & 1.0 & 1.4 & 0.4 \\
Day 6 & 0.4 & 0.3 & 0.9 & 1.3 & 0.4 \\
Day 7 & 0.5 & 0.4 & 1.0 & 1.5 & 0.4 \\
Day 8 & 0.5 & 0.4 & 1.0 & 1.0 & 0.5 \\
Day 9 & 0.4 & 0.4 & 0.9 & 1.2 & 0.4 \\
Day 10 & 0.4 & 0.3 & 0.8 & 0.8 & 0.4 \\
Average & $\mathbf{0 . 4}$ & $\mathbf{0 . 4}$ & $\mathbf{1 . 0}$ & $\mathbf{1 . 2}$ & $\mathbf{0 . 4}$ \\
\hline
\end{tabular}

\subsection{Discussion}

The impact of GSPS on public space provision in North American cities has raised issues related to the overall design scarcely incorporating planning for stationary activities, the limited availability of public services and facilities, the controlled or denied access to these privately-managed pedestrian environments by marginalised social groups (Maitland, 1992; Robertson, 1993; Terranova, 2009). Similarly, empirical findings in Asian cities UPS indicated inadequate availability of public facilities and the prevalence of short duration Transit-Oriented activities (Cui, Allan, Taylor, et al., 2013).

The present study in Hong Kong found that although the publicly-managed MK EPN was mainly designed to cater to high transitgenerated pedestrian flow, during the weekends, this can coexist with observed stationary activities $(n=14,765)$ of a marginalised social group. The average EPN occupancy registers 0.4 person $/ \mathrm{m}^{2}$, that is higher than previous findings in Hong Kong (Tillu, 2011; Villani et al., 2019). During rainy weather, the occupancy reaches 0.5 person $/ \mathrm{m}^{2}$, which is equal to $2 \mathrm{~m}^{2} / \mathrm{person}$. According to established literature, this density represents a crowded space class a) (e.g., lift lobby) (Fruin, 1971), and it is also the entitled open space per person quota by the Hong Kong planning standard guidelines (HKPSG). The occupancy variation in the EPN Part 1 could be explained by the higher number of public (toilets) and commercial services (Fig.1) catering to MDWs in the proximity of MK road, as it appeared from the on-site observations. Similar clustering near migrants-catering commercial facilities are observed in other Asian cities (Elsheshtawy, 2013; Muniandy, 2015; Ostertag, 2016). The presence of incidental seating conditions (railings) and food-related activities proved to be fostering stationary activities in the EPN. These results are aligned with previous studies that found the above conditions together with the presence of covered space (as the EPN is) as a significant variable in supporting stationary activities (Mehta, 2009; Whyte, 1980; Zordan, Talamini, \& Villani, 2019). Finally, the high percentage of social activities, such as chatting, found in the EPN, might indicate the importance of large groups and social activities of MDWs (Law, 2001), and the need for public spaces to accommodate them.

\subsection{Conclusion and Recommendations}

The GSPS of high-density Asian cities have experienced continuous expansion over the past decades. This study contributed to the limited literature on the impact of EPNs on public space provision for stationary uses in the Asian context. In Hong Kong, the study area of this article, this branched network is an opportunity for disadvantaged social groups, such as the MDWs, to perform stationary activities during their day off.

This study, analysing the stationary activities ( $n=14,765)$ during peak hours in the weekends on the EPN of MK, provided new empirical evidence about: (1) Mobility-oriented spaces having the potential to become places of social engagement and interaction among users performing stationary activities; (2) The average density of the EPN space occupation $\left(0.44\right.$ person $\left./ \mathrm{m}^{2}\right)$, when excluding the area used for walking, this reaches 1 person $/ \mathrm{m}^{2}$; the highest occupation density $\left(1.2 \mathrm{person} / \mathrm{m}^{2}\right)$ is observed near food-oriented activities; (3) Most of the activities observed are socially engaged ones; (4) Covered seating areas providing usable public open space in case of adverse weather condition are of vital importance in cities, such as Hong Kong, characterised by high rainfall and scarce public spaces. These findings theoretically contribute to the limited evidence-based literature on the EPN impact on public space provision. In addition, this study may reveal the importance of urban planners and policymakers involved in the shaping of inclusive social realms for increasing 
the wellbeing of disadvantaged social groups. Furthermore, this study advocates an urban design capable of planning spaces, such as mobility spaces, that can easily upgrade to places of social engagement, rather than exclusively serving mobility functions.

Further research may consider a larger number of mobility-oriented case studies backed with space preference or ethnographic surveys. This would culminate in more robust and in-depth results. Recording walking activities, for example through cordon counts, might provide insights on the synergistic variation between pedestrian flow and activities in mobility-oriented spaces. Finally, trustworthiness of stationary data collection in overcrowded linear small urban spaces might be improved through multiple-fixed standpoint observations.

\section{Acknowledgments}

This research was financially supported by a grant from City University of Hong Kong (project No. 7004965). We thank Cheng Yuk Ming for his assistance in data collection. We would like to thank Editage (www.editage.com) for English language editing.

\section{References}

Agyeman, J., \& Zavestoski, S. (2015). Incomplete streets: processes, practices, and possibilities. Oxon: Routledge.

Bechtel, R., \& Zeisel, J. (1987). Observation: the world under a glass. In R. Bechtel, R. Marans, \& W. Michelson (Eds.), Methods in Environmental and Behavioral Research. New York: Van Nostrand Reinhold.

Cheshmehzangi, A., \& Heath, T. (2017). Effects of Temporary Markets on Spatial Inter-relations: A behavioural analysis of a public realm in the UK. Journal of ASIAN Behavioural Studies, 2(3), 41. https://doi.org/10.21834/jabs.v2i3.190

Corbett, M. J., Xie, F., \& Levinson, D. (2009). Evolution of the Second-Story City: The Minneapolis Skyway System. Environment and Planning B: Planning and Design, 36(4), 711-724. https://doi.org/10.1068/b34066

Cui, J., Allan, A., \& Lin, D. (2013). The development of grade separation pedestrian system: A review. Tunnelling and Underground Space Technology, 38, 151-160 https://doi.org/10.1016/j.tust.2013.06.004

Cui, J., Allan, A., Taylor, M. A. P., \& Lin, D. (2013). Developing Shanghai Underground Pedestrian System Under Urbanization: Mobility, Functionality and Equity. Journal of Architecture and Urbanism, 36(4), 283-297. https://doi.org/10.3846/20297955.2012.752933

Elsheshtawy, Y. (2013). Where the sidewalk ends: Informal street corner encounters in Dubai. Cities, 31, 382-393. https://doi.org/10.1016/j.cities.2012.12.001

Fruin, J. (1971). Pedestrian and Planning Design. Metropolitan Association of Urban Designers and Environmental Planners.

Gehl, J. (1987). Life Between Buildings: Using Public Space. New York: Van Nostrand Reinhold. https://doi.org/10.1016/j.progress.2005.01.001

Ghavampour, E., Del Aguila, M., \& Vale, B. (2017). GIS mapping and analysis of behaviour in small urban public spaces. Area, 49(3), 349-358. https://doi.org/10.1111/area.12323

Goličnik Marušic, B. (2016). Discrepancy between likely and actual occupancies of urban outdoor places. Urban Forestry and Urban Greening, 18, 151-162. https://doi.org/10.1016/j.ufug.2016.06.001

Hanan, H. (2017). Every Day Practices and Experiential Urban Space. Asian Journal of Environment-Behaviour Studies, 2(5), 27. https:/doi.org/10.21834/aje-bs.v2i5.220

Harris, A. (2018). Engineering Formality: Flyover and Skywalk Construction in Mumbai. International Journal of Urban and Regional Research, 42(2), 295-314. https://doi.org/10.1111/1468-2427.12525

HKSAR Census and Statistics Department. (2016). 2016 Population By-census.

Lam, P., \& Kung, F. (2004). Innovative and sustainable construction for a footbridge system in congested mongkok, hong kong. HKIE Transactions Hong Kong Institution of Engineers, 11(1), 15-20. https://doi.org/10.1080/1023697X.2004.10667938

Law, L. (2001). Home cooking: Filipino women and geographies of the senses in Hong Kong. Ecumene, 8(Figure 1), 264-283.

Maitland, B. (1992). Hidden cities: The irresistible rise of the North American interior city. Cities, 9(3), 162-169. https://doi.org/10.1016/0264-2751(92)90012-T

Mehta, V. (2009). Look closely and you will see, listen carefully and you will hear: Urban design and social interaction on streets. Journal of Urban Design, 14(1), 29-64. https://doi.org/10.1080/13574800802452658

Muniandy, P. (2015). Informality and the politics of temporariness: Ethnic migrant economies in Little Bangladesh and Little Burma in Kuala Lumpur, Malaysia. International Sociology, 30(6), 561-578. https://doi.org/10.1177/0268580915605649

Nikolaeva, A., Adey, P., Cresswell, T., Lee, J. Y., Nóvoa, A., \& Temenos, C. (2019). Commoning mobility: Towards a new politics of mobility transitions. Transactions of the Institute of British Geographers, 44(2), 346-360. https://doi.org/10.1111/tran.12287

Ostertag, E. (2016). Transitory community hubs: How temporary migration transforms a neighbourhood in Singapore. City, 20(1), 116-129. https://doi.org/10.1080/13604813.2015.1096058

Rasidi, M. H., Jamirsah, N., \& Said, I. (2012). Urban Green Space Design Affects Urban Residents' Social Interaction. Procedia - Social and Behavioral Sciences. 
https://doi.org/10.1016/j.sbspro.2012.12.242

Robertson, K. A. (1993). Pedestrianization strategies for downtown planners skywalks versus pedestrian malls. Journal of the American Planning Association, 59(3), 361370. https://doi.org/10.1080/01944369308975887

Rossini, F. (2019). Temporary urban intervention in the vertical city: a place-making project to re-activate the public spaces in Hong Kong. Journal of Urban Design, 24(2), 305-323. https://doi.org/10.1080/13574809.2018.1507674

Sun, Z., Bell, S., Scott, I., \& Qian, J. (2019). Everyday use of urban street spaces: the spatio-temporal relations between pedestrians and street vendors: a case study in Yuncheng, China. Landscape Research, 00(00), 1-18. https://doi.org/10.1080/01426397.2019.1646231

Tammikakul, P., \& Raksawin, K. (2019). The Pattern of Activity Analysis by GIS in Chiang Mai Public Plaza, Thailand. Asian Journal of Environment-Behaviour Studies, 4(13), 30. https://doi.org/10.21834/aje-bs.v4i13.346

Tan, Z., \& Xue, C. Q. L. (2014). Walking as a Planned Activity: Elevated Pedestrian Network and Urban Design Regulation in Hong Kong. Journal of Urban Design, 19(5), 722-744.

Tang, B. (2017). Is the distribution of public open space in Hong Kong equitable, why not? Landscape and Urban Planning, 161, 80-89. https://doi.org/10.1016/j.landurbplan.2017.01.004

Terranova, C. N. (2009). Ultramodern Underground Dallas: Vincent Ponte's Pedestrian-Way as Systematic Solution to the Declining Downtown. Urban History Review, 37(2), 18. https://doi.org/10.7202/029574ar

Tillu, J. S. (2011). Spatial empowerment: the appropriation of public spaces by Filipina domestic workers in Hong Kong. Master Thesis, Massachusetts Institute of Technology. Retrieved from https://dspace.mit.edu/handle/1721.1/67244

UN-Habitat. (2013). Streets as public spaces and drivers of urban prosperity. Nairobi: UN-Habitat.

Villani, C. (2018). CBD: A NEW POROSITY. In C. Yuan (Ed.), Walkable Cities in High Density China: Livable, Healthy and Sustainable (pp. 83-109). Shanghai: Tongji University Press.

Villani, C., Zordan, M., Talamini, G., \& Cheng, Y. H. (2019). Temporarily Pedestrianized Street in Hong Kong: Governmental Strategy of Implementation and Tactics of Appropriation by Foreign Domestic Workers. In Proceedings of the AESOP 2019 Congress Book of Papers (p. 2559). Venice: The AESOP 2019 Congress.

Von Schönfeld, K. C., \& Bertolini, L. (2017). Urban streets: Epitomes of planning challenges and opportunities at the interface of public space and mobility. Cities, 68(June 2016), 48-55. https://doi.org/10.1016/j.cities.2017.04.012

Wan, S. W. S. (2010). The Role of the Skywalk System in the Development of Hong Kong's Central Business District. Ssrn. https://doi.org/10.2139/ssrn.1699686

Wang, W., Siu, K. W. M., \& Wong, K. C. K. (2016). The pedestrian bridge as everyday place in high-density cities: An urban reference for necessity and sufficiency of placemaking. Urban Design International, 21(3), 236-253. https://doi.org/10.1057/udi.2016.3

Whyte, W. H. (1980). The Social Life of Small Urban Spaces (12th print). New York: Project for Public Spaces. Retrieved from https://www.worldcat.org/title/social-life-ofsmall-urban-spaces/oclc/907415693\&referer=brief_results

Xue, C. Q. L., Manuel, K. K., \& Chung, R. H. Y. (2001). Public space in the old derelict city area - a case study of Mong Kok, Hong Kong. Urban Design International, 6(1), 15-31. https://doi.org/10.1057/palgrave.udi.9000032

Yin, R. K. (1984). Applied social research methods series Case study research: Design and methods. London: SAGE Publications.

Zacharias, J., \& He, J. (2018). Hong Kong's urban planning experiment in enhancing pedestrian movement from underground space to the surface. Tunnelling and Underground Space Technology, 82(July), 1-8. https://doi.org/10.1016/j.tust.2018.07.025

Zordan, M., Talamini, G., \& Villani, C. (2019). The Association between Ground Floor Features and Public Open Space Face-To-Face Interactions: Evidence from Nantou Village, Shenzhen. International Journal of Environmental Research and Public Health, 16(24), 4934. https://doi.org/10.3390/ijerph16244934 